\title{
An Empirical Study on Non-English Majors' English Learning Motivation under Level-based English Teaching
}

\author{
Wei HE \\ School of Foreign Languages, Wuhan Textile University, Wuhan, 430200, China \\ email: lexicraze@wtu.edu.cn
}

Key words: Non-English Majors; English Learning Motivation; level-based English Teaching

\begin{abstract}
The findings from the study offer practical implications to optimize Level-based English Teaching and motivate students. In English teaching, the instructors should foster students' internal motivation, help students establish the reasonable language learning goals, guide students' correct attribution, and in particular arouse their interest. For students, in their learning process, they need to change attitudes and set realistic goals for their study at each stage.
\end{abstract}

\section{Introduction}

Motivation is one of the most influential individual factors in SLA, affecting language learning outcomes and wide attention is paid to it by many researchers and educators. [1] L2 motivation research has always been a flourishing area in SLA studies during the last 50 years. Motivation turns out to be one of the most active individual variables in SLA. [2] As early as the 1950s, Gardner and Lambert in Canada began L2 motivation research and built the classical model under a social psychological approach. Up till now, Western researchers have made a lot of progress in this respect. A considerable amount of literature has been accumulated on the nature of motivation (Keller, 1983; Gardner, 1985; Crookes \&Schmidt, 1991; Williams \& Burden, 1997; Dörnyei \& Ottó, 1998), classifications of motivation and variation in motivation types (Lambert \& Gardner, 1972; Deci \& Ryan, 1985; Hua Huifang, 1998; Gao, et al 2003). [3] With a series of experiments carried out, the relationship between learners' motivation type and their motivational intensity are also discovered (Gao 2003; Ma Guanghui, 2005). Some practical implications of motivation research are also suggested. Currently, motivation research is conducted in a school and classroom environment, combined with a particular education context. Gao Yihong(2003) examine Chinese college undergraduates' English learning motivation types and the relationship between motivation types and motivational intensity with a quantitative investigation. Liu Fengge (2013) conducts a series of studies of learning motivation of L2 learners from the perspective of Dörnyei's L2 Motivational Self System (L2MSS). [4] This study is intended to make an investigation on college students' English learning motivation types and motivational intensity under Level-based English Teaching in order to optimize it and improve the effectiveness of the English language learning and teaching. Besides, the results and major findings in the present study will bring some implications for English teaching and learning, especially in classroom application. [5]

\section{Methodology}

A. Research Questions

Question 1: Do the students from Class A, B and C show any difference in types of motivation?

Question 2: Do the students from Class A, B and C show any difference in motivational intensity?

B. Subjects

The subjects of this study are non-English major undergraduates from 6 classes of Wuhan Textile University. All the subjects are freshmen, who almost finish one year college English under level-based English Teaching. The 6 classes are chosen randomly regardless of their different majors, and each level has 3 classes. 


\section{Instruments}

Questionnaire is recognized as the most effective way to collect quantitative data from a large number of participants as well as to make out the learner's viewpoints. This English learning motivation questionnaire adopted in the present study is the one devised by Gao et al. (2003).

\section{Data collection}

After collecting the questionnaires, every student's response to each item of the question were entered into SPSS version 20.0. All the data are subjected to a variety of analysis to obtain means, deviation and correlation coefficients.

\section{Result and discussion}

Table 1 Descriptive Statistics of the Top Three Motivation Types of Three Classes

\begin{tabular}{|c|c|c|c|c|c|c|c|}
\hline \multirow{3}{*}{$\begin{array}{l}\text { Motivation } \\
\text { types }\end{array}$} & \multicolumn{2}{|c|}{ Class } & \multicolumn{2}{|c|}{$\mathrm{Class}$} & \multicolumn{2}{|c|}{ Class } & \\
\hline & A & & B & & $\mathrm{C}$ & & \\
\hline & Mcan & SD & Mcan & SD & Mean & & SD \\
\hline $\begin{array}{l}\text { immediate } \\
\text { achievement }\end{array}$ & 3.447 & .675 & 3.562 & .660 & 3.605 & .666 & \\
\hline $\begin{array}{l}\text { individual } \\
\text { development }\end{array}$ & 4.032 & .554 & 3.850 & .585 & 3.391 & .834 & \\
\hline $\begin{array}{l}\text { information } \\
\text { medium }\end{array}$ & 3.276 & .734 & 3.153 & .774 & 2.979 & .888 & \\
\hline
\end{tabular}

From Table 1, the mean scores of immediate achievement of the students from Class A, B and C increase by degrees, from 3.447 to 3.562 and to 3.605 . However, the mean scores of individual development and information medium of the students from Class A, B and C decrease successively. The high mean scores appear in Class A, the middle mean scores are in Class B, and the low mean scores are in Class C.

Table2 One-way ANOVA of the Top Three Motivation Types among Three Classes

\begin{tabular}{|c|c|c|c|c|c|c|}
\hline $\begin{array}{l}\text { Motivation } \\
\text { types }\end{array}$ & & Sum of Squares & df & Mean Square & F & Sig. \\
\hline \multirow{2}{*}{$\begin{array}{l}\text { immediate } \\
\text { achievement }\end{array}$} & $\begin{array}{c}\text { Between } \\
\text { Groups }\end{array}$ & 2.261 & 2 & 1.130 & \multirow[t]{2}{*}{2.541} & \multirow[t]{2}{*}{.080} \\
\hline & $\begin{array}{l}\text { Within } \\
\text { Groups }\end{array}$ & 228.639 & 514 & .445 & & \\
\hline \multirow{2}{*}{$\begin{array}{l}\text { individual } \\
\text { development }\end{array}$} & $\begin{array}{c}\text { Between } \\
\text { Groups }\end{array}$ & 37.178 & 2 & 18.589 & \multirow[t]{2}{*}{41.985} & \multirow[t]{2}{*}{.000} \\
\hline & $\begin{array}{l}\text { Within } \\
\text { Groups }\end{array}$ & 227.576 & 514 & .443 & & \\
\hline \multirow{2}{*}{$\begin{array}{l}\text { information } \\
\text { medium }\end{array}$} & $\begin{array}{l}\text { Between } \\
\text { Groups }\end{array}$ & 7.571 & 2 & 3.786 & \multirow[t]{2}{*}{5.904} & \multirow[t]{2}{*}{.003} \\
\hline & $\begin{array}{l}\text { Within } \\
\text { Groups }\end{array}$ & 329.565 & 514 & .641 & & \\
\hline
\end{tabular}

Table 2 shows that immediate achievement of the three classes has no significant differences, because the $p$ value is $0.080>.05$. But the differences in individual development and information medium of the three classes are significant, because of $p=.000, p=.003$ respectively, both of which are less than 0.05 .

In contrast, the bottom three motivation types are different among the three classes. The mean cores of intrinsic interest, learning situation and going abroad are relatively lower than those of other four motivation types in Class A and Class B. The three bottom motivation types in Class C are intrinsic interest, going abroad and social responsibility. 
Table 3 Descriptive Statistics of the Bottom Three Motivation Types of Three Classes

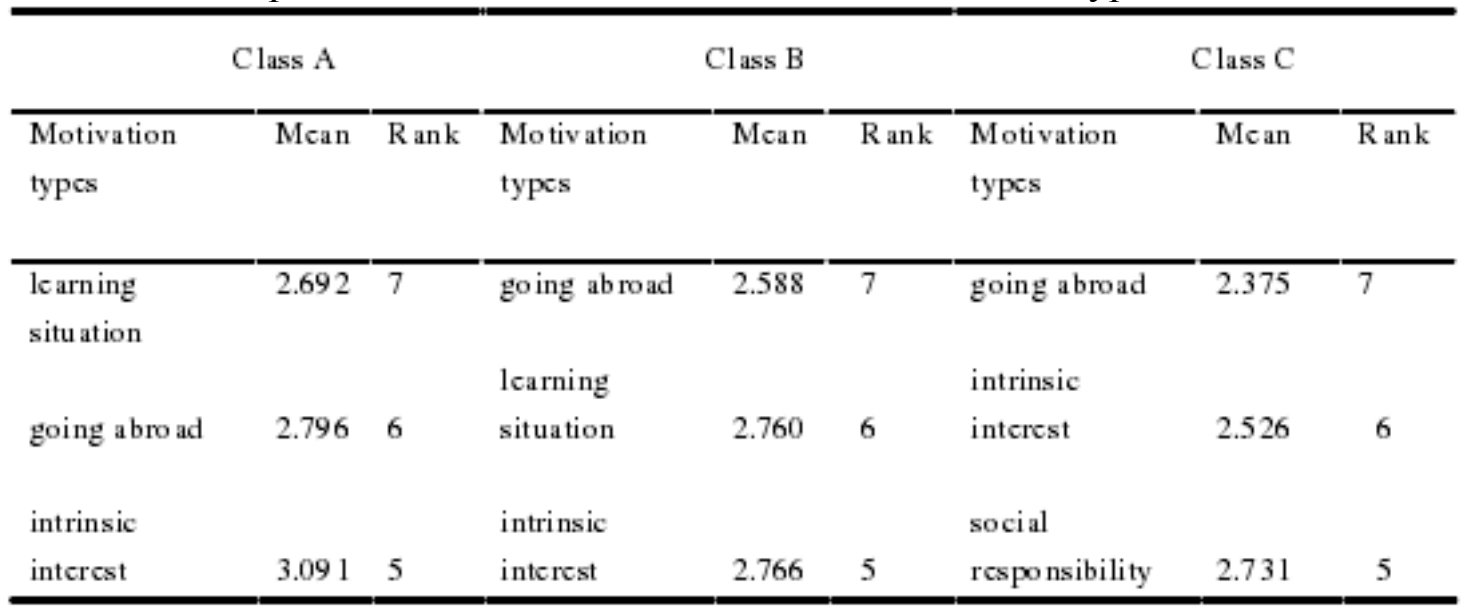

As shown in Table 3, only both intrinsic interest and going abroad are the bottom motivation types of all the three classes.

Table 4 One-way ANOVA of Intrinsic Interest and Going Abroad among Three Classes

\begin{tabular}{lcccccc}
\hline $\begin{array}{l}\text { Motivation } \\
\text { types }\end{array}$ & \multicolumn{1}{c}{ Sum of Squares } & df & Mean Square & F & Sig. \\
\hline intrinsic \\
interest & $\begin{array}{c}\text { Between } \\
\text { Groups } \\
\text { Within }\end{array}$ & 27.324 & 2 & 13.662 & 23.156 & .000 \\
$\begin{array}{c}\text { Groups } \\
\text { Between } \\
\text { Groups } \\
\text { Within }\end{array}$ & 303.265 & 514 & .590 & & \\
\hline Groups abroad & 383.424 & 514 & .746 & 7.553 & 10.126 & .000 \\
\hline
\end{tabular}

As shown in Table 4, the results indicate that the differences in intrinsic interest and going abroad of the three classes are significant, because $p$ value is less than 0.05 . In order to answer Research Question Two "Do the students from Class A, B and C show any difference in motivational intensity?" the descriptive statics and One-way ANOVA have been chosen as the analysis methodologies. Descriptive statistics in Table 4.8 reveal the motivational intensity of the students from Class A, B and C.

Table 5 Descriptive Statistics of Motivational Intensity of Three Classes

\begin{tabular}{ccccccc}
\hline Class & N & Mean & SD & Min & Max & Rank \\
\hline Class A & 170 & 3.157 & .455 & 2.09 & 4.27 & 1 \\
Class B & 177 & 3.021 & .490 & 1.82 & 4.64 & 2 \\
Class C & 170 & 2.955 & .501 & 1.82 & 4.45 & 3 \\
\hline
\end{tabular}

In Table 5, it is evident that the mean scores of motivational intensity of three classes are different. The mean score of Class A is highest, 3.157. Class B comes next, and its mean score is 3.021. The mean score of Class $\mathrm{C}$ is lowest, 2.955.

Table 6 One-way ANOVA of Motivational Intensity among Three Classes

\begin{tabular}{cccccc}
\hline & Sum of Squares & $\mathrm{df}$ & Mean Square & $\mathrm{F}$ & Sig. \\
\hline Between Groups & 3.637 & 2 & 1.818 & 7.809 & .000 \\
Within Groups & 119.694 & 514 & .233 & & \\
Total & 123.331 & 516 & & & \\
\hline
\end{tabular}

In order to verify the significant difference, One-way ANOVA analysis is employed and details are shown as follows (Table 4.9). The results from One-way ANOVA indicate that the difference in motivational intensity among the three classes are significant because of $p=.000<.05$. 
Table 7 Post-hoc Multiple Comparison of Motivational Intensity among Three Classes

\begin{tabular}{ccccccc}
\hline \multirow{2}{*}{ (I) Class } & \multirow{2}{*}{ (J) Class } & $\begin{array}{c}\text { Mean Difference } \\
\text { (I-J) }\end{array}$ & \multirow{2}{*}{ SE } & \multirow{2}{*}{ Sig. } & \multicolumn{2}{c}{$95 \%$ CI } \\
\cline { 7 - 8 } Class A & Class B & .137 & .052 & .009 & .035 & .238 \\
& Class C & .203 & .052 & .000 & .100 & .306 \\
\multirow{2}{*}{ Class B } & Class A & -.137 & .052 & .009 & -.238 & -.035 \\
& Class C & .066 & .052 & .203 & -.036 & .168 \\
\multirow{2}{*}{ Class C } & Class A & -.203 & .052 & .000 & -.306 & -.100 \\
& Class B & -.066 & .052 & .203 & -.168 & .036 \\
\hline
\end{tabular}

Then the results from Post-Hoc multiple comparison of motivational intensity among the three classes are shown in Table 7. According to Table 7, $\mathrm{p}$ value of Class A and Class B is 0.009 , and $\mathrm{p}$ value of Class A and Class $\mathrm{C}$ is 0.000 . Differences in motivational intensities between Class $\mathrm{A}$ and the other two classes are significant because of $p=.000<.05$. But $p$ value of Class $B$ and Class $C$ is $0.203, p>.05$, it shows that there is no significant difference of motivational intensities between students from Class B and Class C.

\section{Conclusions}

\section{A. Major Findings of the Study}

The thesis is mainly to investigate the college students' English learning motivation under Level-based English Teaching, including motivation types, motivational intensity and its' correlation. Comparing motivational intensity of the subjects of the three classes, Class A is highest, and they are most motivated. In addition, subjects' motivational intensity between Class B and Class $\mathrm{C}$ has no significant difference. Intrinsic interest is the only factor that has significantly positive correlation to the subjects' motivational intensity in all classes.

\section{B. Limitations of the Study}

The study looks into non-English majors' learning motivation under level-based English Teaching, yet it is impossible to take account of every aspect. And, motivation is actually dynamic and ever-changing, yet the study only focuses on students' motivation in the first year of college, but changes and development of students' motivation during the two-year college English learning are not involved, which may influence the result of the study.

\section{Suggestions for the Future Study}

English learning motivation is very complex, as there are a lot of relevant factors. Longitudinal study can be conducted to examine the changes of motivation types and motivational intensity during the period of the first two years under Level-based English Teaching. Diversiform research methods can be made attempt to investigate motivation besides questionnaire.

\section{References}

[1] Frank Pajares. SELF-EFFICACY BELIEFS, MOTIVATION, AND ACHIEVEMENT IN WRITING: A REVIEW OF THE LITERATURE[J]. Reading \& Writing Quarterly. 2003 (2)

[2] Rebecca L. Oxford, Judith A. Burry-Stock. Assessing the use of language learning strategies worldwide with the ESL/EFL version of the Strategy Inventory for Language Learning (SILL)[J]. System . 1995 (1)

[3] Bandura A.Social foundations of thought and action: A social cognitive theory. . 1986

[4] Jin-Ah Kim,Anthony W. Lorsbach. Writing Self-Efficacy in Young Children: Issues for the Early Grades Environment [J]. Learning Environments Research. 2005 (2)

[5] BatiaLaufer,T. SimaParibakht. The Relationship Between Passive and Active Vocabularies: Effects of LanguageLearning Context[J]. Language Learning. 2008 (3) 